\title{
Penilaian Dampak Lingkungan Industri Tahu Menggunakan Life Cycle Assessment (Studi Kasus: Pabrik Tahu Sari Murni Kampung Krajan, Surakarta)
}

\author{
Elvis Umbu Lolo ${ }^{1 *}$, Richardus Indra Gunawan², Agerippa Yanuranda Krismani', \\ Yonathan Suryo Pambudi ${ }^{4}$ \\ ${ }^{1,2,3,4}$ Program Studi Teknik Lingkungan, Fakultas Teknik, Universitas Kristen Surakarta \\ *Koresponden email: eumbulolo@yahoo.co.id
}

Diterima : 8 September 2021

Disetujui: 11 Oktober 2021

\begin{abstract}
The problem faced by the tofu industry is waste management. So, it is necessary to do so that tofu waste does not pollute the environment by managing waste and emissions, efficient consumption of energy, materials, and water. One way to identify environmental pollution is by Life Cycle Assessment. This study uses the Life Cycle Assessment (LCA) method. The LCA flow in this study is to determine goals and scopes, create inventory data, make grouping impacts and how much impact they generate, as well as interpreting to provide improvements. The functional unit in this study is $1 \mathrm{~kg}$ of tofu which is produced in 1 day. The results of this study were divided into five impact categories, namely, climate change, the most important being $2195 \mathrm{~kg} \mathrm{CO} 2$, human toxicity potential at $2187 \mathrm{~kg}$ 1,4-Dikchloro benzene, eutrophication at $0.935 \mathrm{~kg}$ PO4, photo oxidant at $0.797 \mathrm{~kg}$ $\mathrm{C} 2 \mathrm{H} 4$, and acidification at $15,915 \mathrm{~kg}$. SO2. The recommended improvement alternative is to make efforts to use water efficiently during the tofu production process, including the need to clean the scale in the steam boiler to increase the volume of steam produced, so that the use of water and energy is more efficient.
\end{abstract}

Keywords: environmental impact assessment, tofu industry, waste, life cycle assessment, Surakarta

\begin{abstract}
Abstrak
Masalah yang dihadapi oleh industri tahu adalah pengelolaan limbah. Sehingga, perlu dilakukan agar limbah tahu tidak mencemari lingkungan dengan pengelolaan limbah dan emisi, efisiensi konsumsi energi, material, dan air. Salah satu cara mengidentifikasi pencemaran lingkungan adalah dengan penilaian daur hidup. Penelitian ini menggunakan metode Life Cycle Assessment (LCA). Alur LCA pada penelitian ini, yaitu menentukan goal dan scope, membuat data inventori, membuat pengelompokan dampak dan berapa besar dampak yang dihasilkan, serta melakukan interpretasi untuk memberikan perbaikan. Unit fungsional pada penelitian ini adalah $1 \mathrm{~kg}$ tahu yang diproduksi dalam sehari. Hasil penelitian ini dibagi dalam lima kategori dampak yaitu, climate change paling utama sebesar $2195 \mathrm{~kg} \mathrm{CO}_{2}$, human toxicity potential sebesar $2187 \mathrm{~kg}$ 1,4-Dikhloro benzene, eutrophication sebesar $0,935 \mathrm{~kg} \mathrm{PO}_{4}$, photo oxidant sebesar $0,797 \mathrm{~kg}_{2} \mathrm{H}_{4}$, dan acidification sebesar $15.915 \mathrm{~kg} \mathrm{SO}$. Alternatif perbaikan yang direkomendasikan, yaitu melakukan upaya efisiensi pemakaian air selama proses produksi tahu, antara lain perlunya dilakukan pembersihan terhadap kerak yang ada di dalam ketel uap untuk memperbesar volume uap yang dihasilkan, sehingga pemakaian air dan energi lebih efisien.
\end{abstract}

Kata Kunci: penilaian dampak lingkungan, industri tahu, limbah, life cycle assessment, Surakarta

\section{Pendahuluan}

Industri tahu yang tergabung dalam koperasi Sumber Agung Krajan, Mojosongo dalam pembuatan tahu masih menggunakan metode yang konvensional. Teknologi yang digunakan masih sangat sederhana dan banyak mengandalkan tenaga manusia, sehingga proses kurang efektif, dan tidak ada sistem yang mengatur pembuangan limbah hasil produksi tahu tersebut. Mayoritas produsen tahu tidak mengolah limbah hasil pembuatan tahu karena biaya yang cukup mahal dan kurangnya pengetahuan dalam pengelolaan limbah [1]. Limbah tahu adalah bahan atau materi buangan hasil proses produksi tahu, yang tidak dimanfaatkan lagi. Limbah tahu berupa limbah padat dan cair. Limbah padat berupa ampas kedelai, limbah cair berupa air sisa 
perendaman, penggumpalan dan juga limbah cair berwarna kuning mudah keabu-abuan yang jika dibiarkan akan berubah berwarna hitam dan berbau busuk [1].

Industri manufaktur di Indonesia termasuk industri rumah tangga perlu memperhatikan prinsip sustainable manufacturing, yaitu pendekatan prinsip triple bottom line untuk berpikir dimana lingkungan, ekonomi, dan sosial harus diperhatikan dengan serius. Industri yang berkelanjutan adalah industri yang meminimalkan dampak pencemaran lingkungan, melestarikan energi dan sumber daya alam, melindungi pekerja, masyarakat dan konsumen serta sehat secara ekonomi. Prinsip tersebut seperti terlihat pada Gambar $1[2]$.

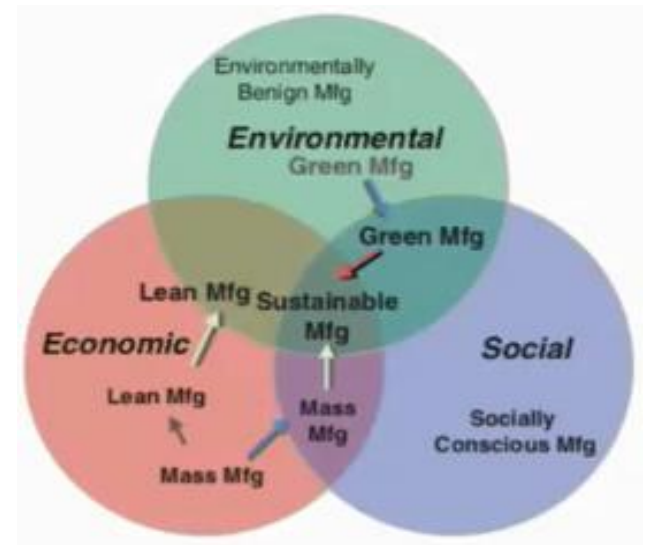

Gambar 1. Prinsip Triple Bottom Line dalam sustainable manufacturing Sumber: Ref. [2]

Dampak lingkungan yang ditimbulkan dari suatu proses atau kegiatan industri memberikan pengaruh yang lebih luas, tidak hanya bagi lingkungan sekitar tetapi juga mempengaruhi lingkungan secara global. Hal ini telah memunculkan kepedulian dalam pengembangan teknik atau metode untuk lebih memahami dan mengurangi dampak tersebut. Salah satu teknik yang dikembangkan adalah Life Cycle Assessment (LCA) [3]. Dengan LCA dapat diketahui sumber daya yang digunakan (input) suatu proses dan material-material yang dihasilkan (output) suatu proses[4]. Life cycle assessment (LCA) merupakan suatu metode atau alat yang digunakan untuk menganalisis dampak lingkungan yang terjadi akibat berlangsungnya proses pembuatan suatu produk [5]. Metodologi dalam LCA terdapat empat komponen meliputi definisi tujuan dan ruang lingkup, LCI (Life Cycle Inventory), penilaian dampak, dan penilaian improve [6].

Manfaat implementasi LCA pada proses produksi di industri, yaitu (1) mendapatkan output yang bersifat kuantitatif bukan hanya kualitatif; (2) control supply chain dan laporan akurat dalam inventory data; (3) membantu penghematan pada bagian procurement dengan kegiatan inventory data sehingga secara tidak langsung akan terdata penggunaan secara akurat; (4) mendapatkan hasil kuantitatif beberapa dampak lingkungan yang lebih komprehensif karena sudah mempertimbangkan input dari: (a) material, (b) emisi ke udara, (c) buangan ke air, (d) emisi buangan ke tanah, (e) energi, (f) waste to treatment; (5) mendapatkan hasil audit energi yang lebih komprehensif karena sudah mempertimbangkan input dari: (a) material, (b) emisi ke udara, (c) emisi/buangan ke air, (d) emisi/buangan ke tanah, (e) energi, (f) waste to treatment; (6) menemukan hotspot sepanjang sistem produk untuk memproduksi sebuah produk; (7) membantu lebih akurat untuk melakukan continuous improvement; (8) mengoptimalkan proses produksi produk sepanjang tahapan proses produksi sebuah produk di industri; (9) menyumbang pada sistem database LCA regional, nasional dan internasional; (10) setelah diperoleh proses produksi yang optimal (efisien) seharusnya akan memperkecil biaya pokok produksi atau dengan kata lain menghemat biaya produksi; (11) hasil LCA dapat diajukan untuk sertifikasi Ecolabel tipe III atau Environmental Product Declaration (EPD) [7]; (12) membantu marketing, sehingga pada akhirnya membantu meningkatkan pendapatan perusahaan; (13) menjadi salah satu penilaian pada Kriteria PROPER, terutama untuk hijau dan emas, sehingga memudahkan pemerintah untuk mengambil kebijakan secara kuantitatif dengan solusi yang lebih terukur [8].

Industri tahu di Kampung Krajan, Mojosongo, Surakarta, dalam proses produksinya belum menjalankan konsep Life Cycle Assesment, hal ini dapat terlihat dari penggunaan energi yang belum efisien, limbah padat yang belum ditangani dengan baik, dan air limbah yang mengandung bahan organik tinggi sehingga 
menimbulkan pencemaran sungai. Berdasarkan hal tersebut, peneliti ingin melakukan penelitian untuk menghitung penggunaan material, air dan energi, menganalisis, dan mengidentifikasi potensi dampak lingkungan, dan menyajikan rekomendasi perbaikan untuk menurunkan dampak lingkungan.

\section{Metode Penelitian}

Waktu dan Tempat Penelitian

Waktu dan Tempat Penelitian ini dilaksanakan pada Januari - Mei 2021. Lokasi penelitian di Home Industri SM Bapak Aco, Kampung Krajan RT.3/RW.3, Mojosongo, Surakarta yang dapat dilihat pada Gambar 2.

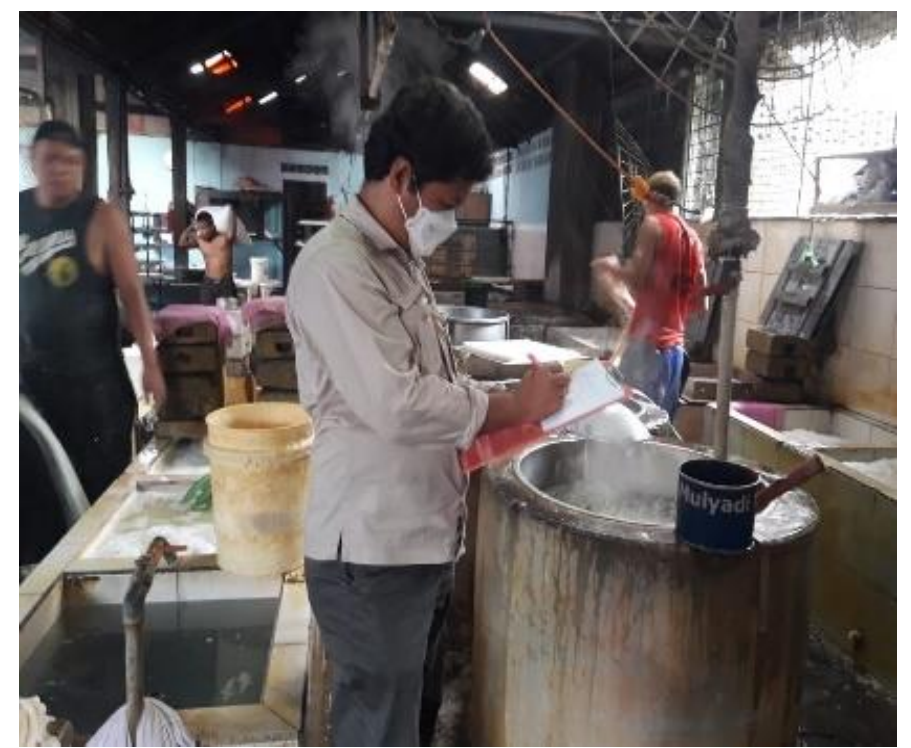

Gambar 2. Lokasi penelitian home industri SM Bapak Aco, Kampung Krajan, Mojosongo, Surakarta. Sumber: Data penelitian, 2021

\section{Prosedur}

Tahap penelitian yang dilakukan terdiri dari studi pustaka, observasi lapangan, wawancara, dan pengolahan data. Metode yang digunakan dalam penelitian ini mengikuti prosedur LCA menurut ISO 14040. Pendekatan yang digunakan adalah deskriptif kuantitatif untuk mengkaji aspek lingkungan. Data yang diperoleh selanjutnya diolah dan dianalisis menggunakan software OpenLCA 1.013 untuk dilakukan fase assessment. Perhitungan dampak dilakukan berdasarkan metode CML 2001 (baseline). Unit fungsional yang dipakai adalah $1 \mathrm{~kg}$ tahu yang diproduksi dalam 1 hari sampai ke pasar tradisional terdekat yaitu pasar Mojosongo.

Standar sebuah Life Cycle Assessment dilakukan dalam empat fase yang berbeda seperti yang diilustrasikan pada Gambar 3. Metodologi dalam Life Cycle Assessment (LCA) terdiri atas empat fase yaitu:

1. Goal and Scope Definition

2. Life Cycle Inventory (LCI)

3. Life Cycle Impact Assessment (LCIA)

4. Interpretation 


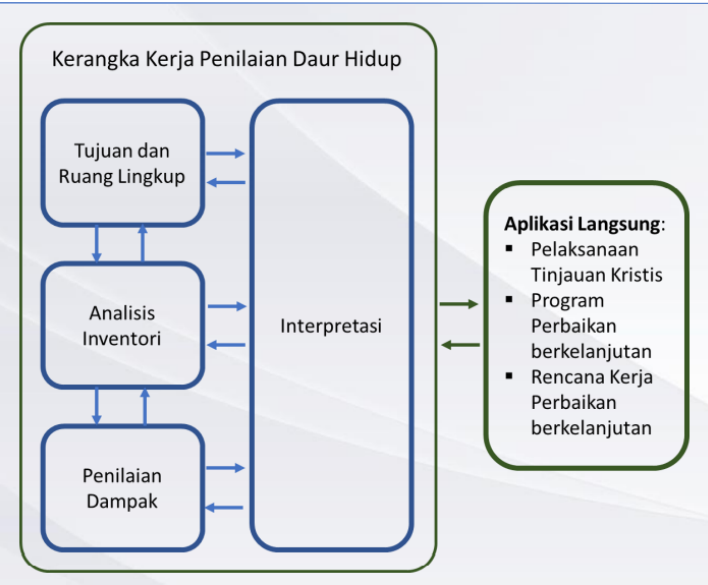

Gambar 3. Kerangka kerja penilaian daur hidup Sumber: Ref. [9]

\section{Analisis Data}

Software openLCA 1.103 ini merupakan salah satu software generasi terbaru dari greendelta dan biasanya digunakan dalam Life Cycle Assessment (LCA). Software openLCA merupakan software yang bersifat open publik yang dapat diakses secara gratis. Dimana software ini mampu membantu menganalisis aspek-aspek lingkungan dari produk maupun jasa secara sistematis dan konsisten.

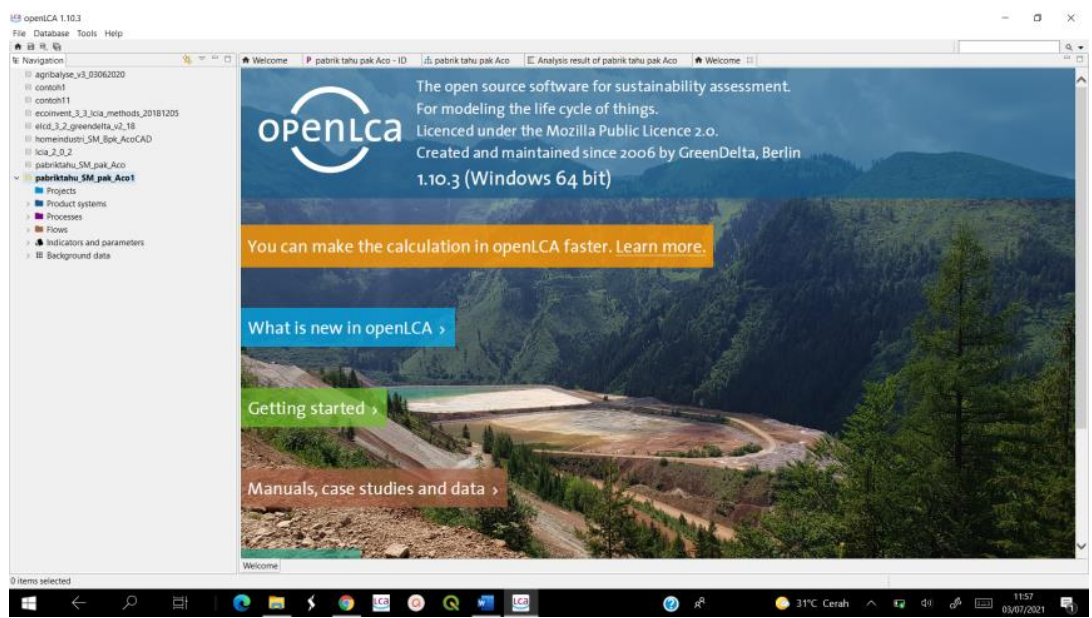

Gambar 4. Tampilan awal Software OpenLCA 1.103

Sumber: Ref. [10][11]

Menurut [11], proses dan fitur yang tersedia pada software OpenLCA secara garis besar dapat dijelaskan sebagai berikut:

1. Flows, merupakan input dan output dari seluruh produk, material maupun energi pada proses produksi sebuah produk. Tipe flow yang terdapat pada OpenLCA adalah (a) elementary flows, material atau energi dari lingkungan yang masuk dan keluar dari/ke proses produksi; (b) product flows, material atau energi yang bertukar pada saat proses produk; (c) waste flows, material atau energi yang keluar dari proses produk.

2. Database, pada penelitian ini database yang dipakai adalah: ELCD database 3.2, Agribalyse v3.0.1, dan Bioenergidat-18 yang tidak berbayar pada openLCA Nexus [12].

\section{Hasil dan Pembahasan}

\section{Tujuan dan ruang lingkup proses pembuatan tahu}

Sebelum menentukan tujuan dan ruang lingkup, perlu ditentukan definisi unit fungsional yang dibahas. Unit fungsional pada penelitian ini adalah produksi $1 \mathrm{~kg}$ tahu untuk satu hari. Tujuan yang akan dicapai adalah 
mengetahui hal apa saja dan berapa besarnya dampak pada lingkungan yang dihasilkan dari penggunaan material dan energi ketika melakukan proses pembuatan tahu. Ruang lingkupnya melakukan analisis pada input proses (material) dan energi pada tiap-tiap tahapan dalam proses pembuatan tahu mulai dari produksi kacang kedelai, kacang kedelai dikirim ke konsumen, proses pembuatan tahu di Pabrik Tahu Sari Murni Pak Aco, sampai pengiriman ke konsumen dalam hal ini ke pasar tradisional, rumah makan dan rumah tangga. Sehingga dalam hal ini ruang lingkupnya cradle to gate seperti dijelaskan pada Gambar 5.

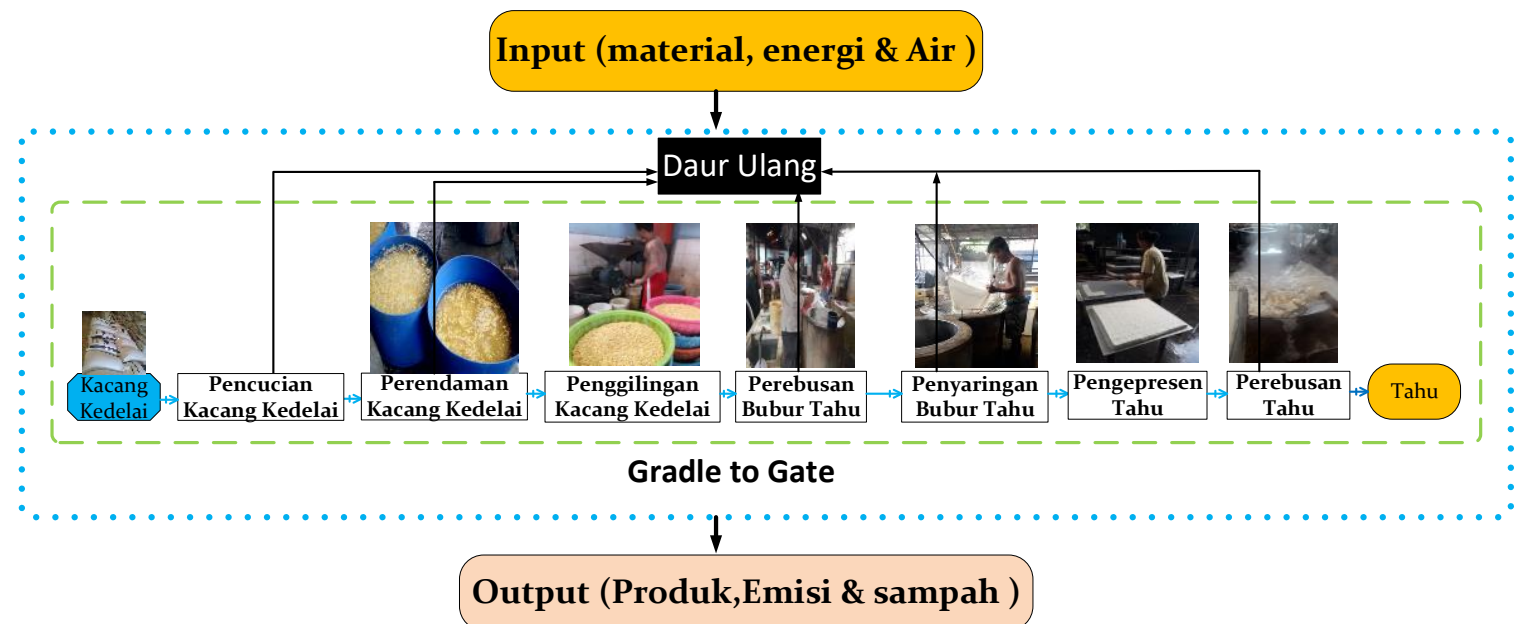

Gambar 5. Batas sistem Gradle to Gate produksi Tahu SM Bapak Aco

Sumber: Data penelitian, 2021

\section{Life Cycle Inventory (LCI)}

Proses pembuatan tahu dilakukan selama 8 jam per hari sampai pada tahap pengiriman ke konsumen. Peneliti menentukan ruang lingkup penelitian ini adalah masuk kategori cradle to gate karena analisa dilakukan mulai dari tahap pengolahan dan penggunaan bahan baku hingga proses produksi. Hal ini dapat dijelaskan pada Gambar 6. Pada Gambar 6 bahwa proses pengolahan tahu SM Bapak Aco, terbagi dalam tiga bagian yaitu, input dimulai dengan penyiapan bahan baku kacang kedelai, pemakaian energi, dan penambahan asam cuka. Kemudian dilakukan proses pengolahan kacang kedelai melalui beberapa tahap, mulai dari pencucian, perendaman kacang kedelai, penggilingan kacang kedelai, perebusan bubur kedelai dengan menambahkan asam cuka $\left(\mathrm{CH}_{3} \mathrm{COOH}\right)$, penyaringan, dan pencetakan tahu dan mengirimkan ke konsumen.

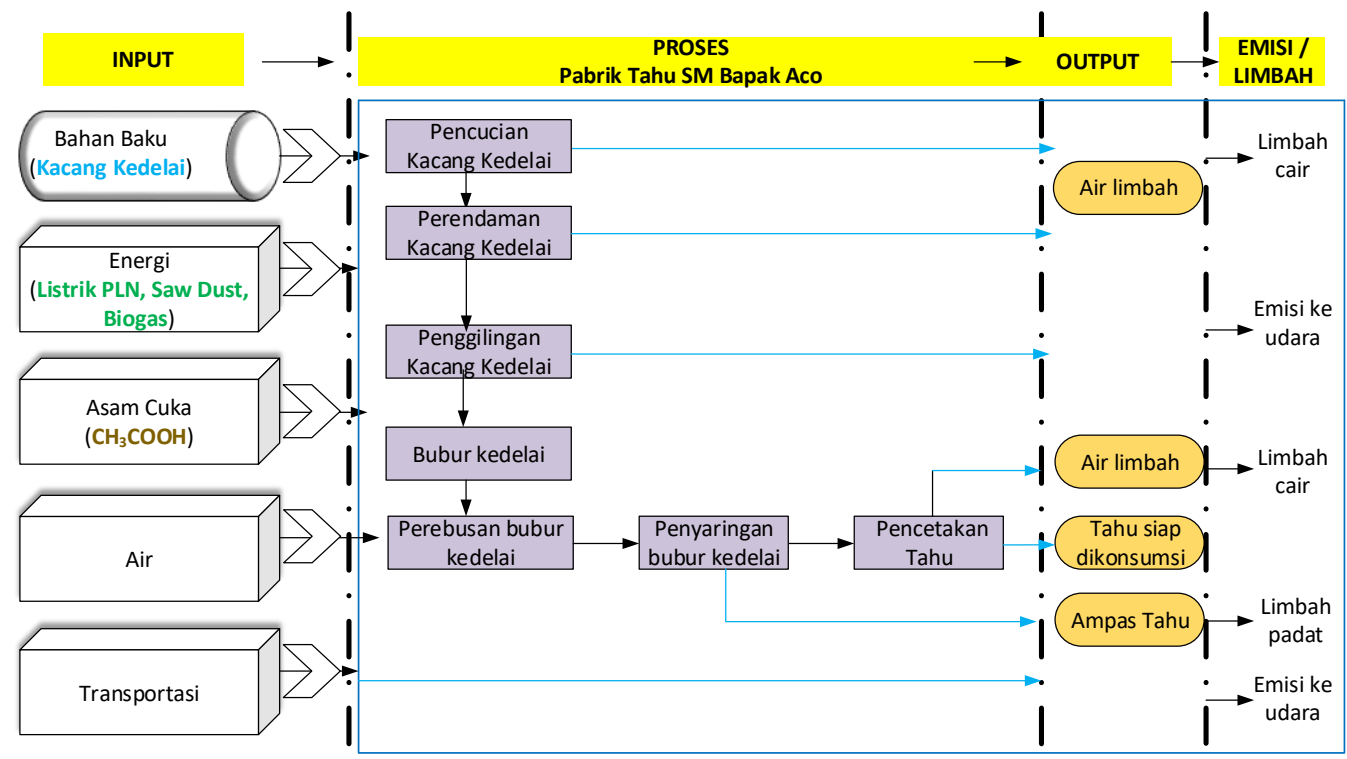

Gambar 6. Input, proses, dan output pengolahan tahu SM Bapak Aco, Krajan, Mojosongo Sumber: Data penelitian, 2021 
Berdasarkan neraca input, proses, dan output pada Gambar 6 diperoleh data inventori pabrik tahu SM Bapak Aco, seperti terlihat pada Tabel 1. Output emisi gas $\mathrm{CO}_{2}, \mathrm{CH}_{4}, \mathrm{~N}_{2} \mathrm{O}, \mathrm{PO}_{4}{ }^{3-}, \mathrm{SO}_{2}$, dan $\mathrm{NO}_{2}$ dihasilkan dari pembakaran serbuk gergaji, pengolahan limbah cair tahu menjadi biogas dan pemakaian energi listrik. Perhitungan emisi gas berdasarkan standar IPCC Tahun 2006 untuk sektor energi [13].

Tabel 1. Data inventori pabrik tahu SM Bapak Aco, Krajan, Mojosongo

\begin{tabular}{|c|c|c|c|c|c|}
\hline Input & Jumlah & Satuan & Output & Jumlah & Satuan \\
\hline Kedelai & 350 & $\mathrm{Kg}$ & Tahu & 250 & $\mathrm{~kg}$ \\
\hline \multirow[t]{2}{*}{ Air } & 3010 & liter & Air limbah & 2600 & liter \\
\hline & & & Ampas tahu & 300 & $\mathrm{~kg}$ \\
\hline Listrik & 45,7 & kwh & $\mathrm{CO}_{2}$ & 24,80 & $\mathrm{~kg}$ \\
\hline Serbuk gergaji/ & 1620 & kwh & $\mathrm{CH}_{4}$ & 12 & $\mathrm{~kg}$ \\
\hline \multicolumn{6}{|l|}{ Wood saw dust } \\
\hline Biogas & 29,042 & Kwh & $\mathrm{N}_{2} \mathrm{O}$ & 0,585 & $\mathrm{~kg}$ \\
\hline \multirow{3}{*}{$\begin{array}{l}\text { Asam cuka/acetic } \\
\text { acid/ } / \mathrm{CH}_{3} \mathrm{COOH}\end{array}$} & 2 & liter & $\mathrm{PO}_{4}^{3-}$ & 0,066 & $\mathrm{~kg}$ \\
\hline & & & $\mathrm{SO}_{2}$ & 0,044 & $\mathrm{~kg}$ \\
\hline & & & $\mathrm{NO}_{2}$ & 0.42 & $\mathrm{~kg}$ \\
\hline
\end{tabular}

Sumber: Data penelitian (2021)

\section{Life Cycle Impact Assesment (LCIA) proses pembuatan tahu}

Life Cycle Impact Assessment (LCIA) merupakan tahap ketiga yang bertujuan untuk mengelompokkan dan menilai berapa besar dampak yang ditimbulkan terhadap lingkungan berdasarkan input data pada tahap dua yaitu LCIA. Penelitian dampak ini menggunakan openLCA dengan metode CML 2001. Input data yang sesuai dengan life cycle inventory, kemudian dimasukkan ke dalam openLCA yang akan menghasilkan sebuah "sankey diagram' yang menggambarkan aktifitas supply chain proses pembuatan tahu. Sankey diagram ini menggambarkan secara keseluruhan sistem yang akan diteliti dan berapa besarnya dampak dari setiap proses yang ada pada sistem tersebut. Adapun kategori dampak yang dinilai dengan menggunakan metode CML 2001 ecoinvent dapat dilihat pada Tabel 2.

Tabel 2. Impact kategori pabrik tahu SM Pak Aco dengan OpenLCA

\begin{tabular}{lll}
\hline No. Impact category & Reference unit & Result \\
\hline 1. Acidification & $\mathrm{kg} \mathrm{SO}_{2} \mathrm{eq}$ & 27,92294 \\
2. Eutrophication & $\mathrm{kg} \mathrm{PO}_{4} \mathrm{eq}$ & 1,987027 \\
3. Climate Change & $\mathrm{kg} \mathrm{CO}_{2} \mathrm{eq}$ & 4026,078 \\
4. Human toxicity & $\mathrm{kg} \mathrm{1}^{1,4-\mathrm{DB}} \mathrm{eq}$ & 436,9892 \\
5. Photochemical oxidation & $\mathrm{kg} \mathrm{C}_{2} \mathrm{H}_{4} \mathrm{eq}$ & 0,085625 \\
\hline
\end{tabular}

Sumber: Data penelitian (2021)

\section{Acidification}

Berdasarkan Tabel 2 dapat dijelaskan dampak-dampak terhadap lingkungan sebagai berikut:

Polusi yang bersifat mengasamkan memiliki banyak dampak pada tanah, air, air bawah tanah, air permukaan, organisme biologis, ekosistem, dan material. Polusi yang bersifat mengasamkan yang paling utama adalah $\mathrm{SO}_{2}, \mathrm{NO}_{2}$ [14]. Pada penelitian ini, tahapan yang paling besar memberikan sumbangan adalah tahap penggilingan sebesar 51,61\% dan tahap perebusan bubur tahu sebesar 47,54\%. Hal ini disebabkan bahan bakar untuk menggiling kacang kedelai menggunakan listrik dengan sumber utama bahan bakar fosil batubara. Pembakaran batu bara akan menghasilkan gas $\mathrm{SO}_{2}$. Selain emisi $\mathrm{SO}_{2}$ parameter lain yang memberikan kontribusi terhadap asiditas adalah emisi $\mathrm{NO}_{2}$, yang dihasilkan dari proses pembakaran serbuk gergaji kayu untuk memanaskan steam boiler guna menghasilkan panas yang dipakai untuk memasak bubur tahu.

\section{Eutrofikasi}

Eutrofikasi adalah proses gradual timbulnya penyuburan pada waduk secara berlebihan yang diakibatkan oleh senyawa nutrien terutama nitrogen dan fosfor [15]. Eutrophication mencakup semua dampak potensial 
pada tingkat nutrisi makro lingkungan yang berlebihan, seperti nitrogen $(\mathrm{N})$ dan fosforus $(\mathrm{P})$. Konsentrasi nutrisi yang tinggi dapat menyebabkan air di permukaan tidak dapat digunakan sebagai air minum. Pada ekosistem air, peningkatan produksi biomassa dapat berakibat tingkat oksigen yang rendah, karena adanya tambahan konsumsi oksigen dalam dekomposisi biomassa (yang diukur sebagai biological oxygen demand). Eutrofikasi dapat mempengaruhi ekosistem air atau pencemaran terhadap ekosistem air akibat dari terlalu banyaknya nutrien didalamnya. Hal tersebut menyebabkan pertumbuhan tanaman yang berlebihan seperti ganggang di sungai. Gas-gas yang berpotensi untuk memberikan dampak eutrofikasi adalah amonia, nitrat, oksida nitrogen dan fosfor [16]. Dalam penelitian ini tahapan perebusan tahu memberikan dampak lingkungan paling besar yaitu $47 \%$ karena ada sebagian sisa perebusan yang dibuang ke saluran dan masuk ke sungai sekitar pabrik tahu. Limbah cair pabrik tahu mengandung bahan organik tinggi, hal ini ditunjukkan dengan nilai BOD, COD dan phosphate yang besar [17]. Jika limbah cair tahu dibuang ke sungai kandungan phosphate dalam bubur tahu akan terurai dalam perairan sungai dan mencemari sungai.

\section{Climate Change}

Global warming potential adalah potensi kontribusi total terhadap pemanasan global akibat emisi satu unit gas, relatif terhadap satu unit gas acuan yaitu $\mathrm{CO}_{2}$ yang diberi nilai 1 [18]. Global warming potential telah dikembangkan untuk memungkinkan perbandingan dampak pemanasan global dari masing-masing jenis gas yang masuk dalam kategori gas rumah kaca yaitu $\mathrm{CH}_{4}, \mathrm{~N}_{2} \mathrm{O}$ dan $\mathrm{CO}_{2}$ [19]. Dampak dari pemanasan global adalah adanya perubahan iklim (climate change). Perubahan iklim dapat didefinisikan sebagai perubahan suhu global yang disebabkan oleh efek rumah kaca akibat dari aktivitas manusia. Saat ini, kenaikan emisi dapat berpengaruh nyata terhadap perubahan iklim. Perubahan iklim adalah salah satu efek lingkungan dari kegiatan ekonomi dan sosial yang paling sulit ditangani karena ruang lingkupnya terlalu luas. Jenis gas yang memiliki pengaruh terhadap perubahan iklim adalah metana dan $\mathrm{CO}_{2}[16]$.

Industri tahu SM Bapak Aco, menggunakan energi dari bahan bakar serbuk gergaji kayu, biogas dan listrik PLN, sehingga menimbulkan emisi $\mathrm{CO}_{2}, \mathrm{CH}_{4}, \mathrm{~N}_{2} \mathrm{O}, \mathrm{SO}_{2}, \mathrm{NO}_{2}$, dan debu. Pada penelitian ini tahapan perebusan bubur tahu merupakan tahapan paling besar yang berkontribusi terhadap dampak lingkungan sebesar $57,48 \%$ karena menggunakan serbuk gergaji dengan nilai energi $16200 \mathrm{kwh}$. Serbuk gergaji kayu lebih tinggi menghasilkan emisi jika dibandingkan dengan LPG dan biogas, karena proses pembakarannya tidak sempurna yang menghasilkan debu dan jelaga. Nilai faktor emisi $\mathrm{CO}_{2}, \mathrm{CH}_{4}$, dan $\mathrm{N}_{2} \mathrm{O}$ pembakaran serbuk kayu bakar juga jauh lebih besar dari faktor emisi $\mathrm{CO}_{2}, \mathrm{CH}_{4}$, dan $\mathrm{N}_{2} \mathrm{O}$ pembakaran biogas. Penggunaan energi berikutnya yang besar untuk tahap perebusan bubur tahu adalah penggunaan biogas dengan nilai energi sebesar 29,042 kwh. Terakhir, menggunakan listrik PLN untuk mesin penggiling kacang kedelai, pompa air dan lampu dengan nilai energi 5,64 kwh

Tabel 3. Persentase kontribusi dampak pada tahapan produksi tahu Sari Murni Bapak Acok

\begin{tabular}{lccccc}
\hline Tahap & $\begin{array}{c}\text { Acidification } \\
\text { Potential }\end{array}$ & Climate Change & $\begin{array}{c}\text { Eutrophication } \\
\text { Potential }\end{array}$ & $\begin{array}{c}\text { Photochemical } \\
\text { Oxidation }\end{array}$ & $\begin{array}{c}\text { Human } \\
\text { Toxicity }\end{array}$ \\
\hline Pencucian & $0,10 \%$ & $0,13 \%$ & $0,01 \%$ & $0,02 \%$ & $0 \%$ \\
Perendaman & $0,2 \%$ & $0,25 \%$ & $0,02 \%$ & $0,05 \%$ & $0,01 \%$ \\
Penggilingan & $51,61 \%$ & $41,57 \%$ & $52,24 \%$ & $63,08 \%$ & $90,71 \%$ \\
Perebusan & $47,54 \%$ & $57,48 \%$ & $47,05 \%$ & $36,46 \%$ & $9,14 \%$ \\
Penyaringan & $0,55 \%$ & $0,57 \%$ & $0,67 \%$ & $0,38 \%$ & $0,15 \%$ \\
\hline
\end{tabular}

Sumber: Data penelitian (2021)

\section{Human Toxicity}

Toksisitas manusia berkaitan dengan efek zat beracun terhadap manusia berupa gangguan pernafasan yang disebabkan oleh zat anorganik yang terlepas ke udara dan dinyatakan sebagai 1,4 dcb [20]. Dalam penelitian ini tahapan yang memberikan dampak human toxicity adalah pada tahap penggilingan dan perebusan tahu masing-masing $90,71 \%$ dan 9,14\% dimana pembakaran serbuk gergaji kayu menghasilkan particulate matter (PM) dengan ukuran yang bervariasi, yang dapat menyebabkan gangguan pernapasan. Sistem kelistrikan di Indonesia masih menggunakan batubara dimana proses pembakaran menghasilkan emisi gas dan PM.

\section{Photochemical Oxidation}

Photochemical Oxidation adalah jenis polusi udara sekunder yang terbentuk di troposfer disebabkan oleh adanya reaksi sulfat yang terbentuk dari pembakaran bahan bakar fosil serta menciptakan bahan kimia lainnya. Biasanya terjadi di udara pada saat ada sinar matahari akan tetapi kelembaban rendah. Hal tersebut terjadi 
karena adanya oksida nitrogen yang mudah menguap. Dampak kategori tergantung pada jumlah karbon monoksida (CO), sulfur dioksida $\left(\mathrm{SO}_{2}\right)$, nitrogen oksida (NO), dan amonium. Photochemical Oxidation atau asap fotokimia dapat menyebabkan masalah pernapasan, iritasi mata, dan lain sebagainya. Dalam penelitian ini tahapan perebusan tahu memberikan dampak lingkungan paling besar yaitu $47 \%$. Pada penelitian ini salah satu proses produksi tahu yang menghasilkan dampak photochemical oxidation adalah proses pembakaran sisa gergaji kayu dan biogas yang dihasilkan dari proses penguraian secara anaerobik. Karena pada proses pembakaran serbuk gergaji kayu dan biogas menghasilkan emisi $\mathrm{CO}, \mathrm{SO}_{2}$, dan $\mathrm{NO}$.

\section{Interpretasi}

Interpretasi merupakan langkah terakhir dalam tahapan LCA. Rencana tindakan yang akan dibuat didasarkan pada hasil interpretasi. Metode analisis yang dilakukan untuk menentukan isu-isu lingkungan adalah dengan metode pendekatan analisis kontribusi yang dilanjutkan dengan analisis perbaikan.

\section{Analisis Kontribusi}

Tujuan dari analisis kontribusi adalah untuk mengetahui tahapan dalam produksi tahu yang memiliki kontribusi paling dominan sehingga pengambilan keputusan dalam menentukan langkah perbaikan menjadi tepat dan efektif. Tabel 3 menjadi dasar pertimbangan untuk menentukan alternatif perbaikan lingkungan. Berdasarkan Tabel 3 terlihat bahwa terdapat 2 proses dalam produksi tahu yang memberikan kontribusi tertinggi, yaitu pada proses penggilingan dan perebusan tahu.

\section{Analisa Perbaikan}

Analisis perbaikan dilakukan berdasarkan hasil analisis kontribusi. Upaya perbaikan dalam LCA yaitu industri harus mengaplikasikan program Resource Efficiency and Cleaner Production (RECP) atau efisiensi sumber daya dan produksi bersih, yaitu konsep terintegrasi dan berkelanjutan penerapan pencegahan praktik lingkungan dan semua teknik produktivitas pada proses, produk dan layanan untuk meningkatkan efisiensi dan mengurangi risiko terhadap manusia dan lingkungan. RECP meliputi beberapa hal yaitu produksi bersih/cleaner production, eco-efficiency/ konsep produksi yang meminimumkan penggunaan bahan baku, air, energi serta dampak lingkungan per unit produk, meminimalkan buangan/waste minimization, industri ramah lingkungan/green productivity, pencegahan polusi/pollution prevention, dan pengurangan penggunaan racun/toxics use reduction [21].

Menurut PERMEN lingkungan hidup dan kehutanan No 1 Tahun 2021 tentang PROPER, salah satu yang harus dilakukan oleh industri dalam proses produksinya adalah mengaplikasikan konsep produksi bersih, yaitu better process control, yaitu memantau dan mengontrol proses dan peralatan yang digunakan sehingga mereka selalu berfungsi sangat efisiensi dan dengan tingkat pemborosan terendah; technology change, yaitu mengganti teknologi baru yang lebih efisien atau menghasilkan lebih sedikit limbah; input change, yaitu memilih input yang efisien, efektif dan/atau menimbulkan bahaya minimum untuk lingkungan dan kesehatan manusia; dan equipment modification, yaitu membuat peralatan yang ada lebih efisien dan kurang boros. Perbaikan yang dilakukan antara lain:

a. Dari hasil perhitungan life cycle assessment dengan aplikasi openLCA terlihat bahwa hotspot permasalahan lingkungan yang paling besar adalah pada pemakaian energi pada saat proses produksi tahu antara lain, steam boiler untuk merebus bubur tahu dengan bahan bakar sisa gergaji kayu dan biogas, listrik PLN untuk menggerakkan pompa air dan mesin penggilingan kacang kedelai menjadi bubur tahu. Perbaikan yang dilakukan antara lain:

- Equipment modification, membuat peralatan yang ada lebih efisien dan tidak boros yaitu:

1. Melakukan upaya efisiensi pemakaian air selama proses produksi tahu, antara lain steam boiler/ketel uap perlu dikeruk kerak-kerak yang ada dalam ketel uap untuk memperbesar volume uap yang dihasilkan, sehingga pemakaian air lebih efisien.

2. Pompa air dan mesin penggilingan kacang kedelai yang telah lama masa pakainya, perlu dipertimbangkan agar diganti dengan mesin yang baru sehingga volume air yang dipompa lebih cepat dan banyak dalam durasi waktu yang singkat.

3. Demikian juga pipa-pipa penyalur uap air dari steam boiler perlu diganti dengan yang baru jika kerakkerak telah memperkecil ukuran diameter pipa. Pipa-pipa yang telah mengalami korosi perlu diganti untuk mengurangi dampak kesehatan pada konsumen tahu Bapak Aco.

4. Untuk pengendalian asap dan partikel debu yang dihasil pembakaran sisa gergaji dan kayu bekas, cerobong asap perlu lebih ditinggikan dari kondisi sekarang ini, dengan tujuan untuk mengurangi dampak bagi masyarakat sekitar dan pekerja pabrik tahu Sari Murni Bapak Aco. 
- Technology change, yaitu mengganti teknologi baru yang lebih efisien atau menghasilkan lebih sedikit limbah yaitu pemakaian air untuk proses merendam kacang kedelai, merebus bubur tahu, penyaringan bubur tahu, pengepresan tahu, dan merebus tahu tidak menggunakan ember kecil tapi dengan menggunakan kran air sehingga pemakaian air lebih terkontrol dan hemat.

- Better process control, yaitu memantau dan mengontrol proses dan peralatan yang digunakan sehingga mereka selalu berfungsi sangat efisiensi dan dengan tingkat pemborosan terendah misalnya perlu dibuat instruksi kerja (IK) sederhana, bagi semua pekerja di pabrik tahu Sari Murni Bapak Aco, untuk dipatuhi jika selesai menggunakan air harus segera mematikan stop kran air dan mematikan pompa air jika air di tandon telah penuh, serta mematikan mesin penggilingan kacang kedelai jika selesai menggiling kacang kedelai.

- Input change, yaitu memilih input yang efisien, efektif dan/atau menimbulkan bahaya minimum untuk lingkungan dan kesehatan manusia misalnya:

1. Selama musim hujan, dalam proses produksi bisa menggunakan air hujan untuk mengurangi pemakaian listrik dengan pompa air. Untuk itu perlu diteliti kualitas air hujan jika memenuhi syarat kualitas air bersih dapat digunakan.

2. Mengganti pemakaian sisa gergaji kayu dan sisa kayu dalam pemanasan ketel uap untuk merebus bubur tahu dengan menggunakan biogas dari limbah cair tahu, sehingga mengurangi gas $\mathrm{CO}_{2}, \mathrm{SO}_{2}, \mathrm{NO}_{2}, \mathrm{CH}_{4}$ dan partikel debu ke lingkungan pabrik Sari Murni Pak Aco.

b. Hotspot permasalahan lingkungan berikutnya adalah transportasi, dimana kacang kedelai yang dipakai dalam proses pembuatan tahu menggunakan kacang kedelai dari negara Amerika Serikat. Sehingga memerlukan alat transportasi kapal laut dan jarak yang jauh ke Indonesia. Sehingga dengan transportasi kapal laut dan jarak yang jauh ini memerlukan bahan bakar fosil yang besar dan menghasilkan emisi gas buang ke udara dalam bentuk gas $\mathrm{CO}_{2}, \mathrm{NO}_{2}$, dan $\mathrm{SO}_{2}$.

Perbaikan yang diusulkan adalah Input change yaitu perlu mempertimbangkan pemakaian kacang kedelai produksi dalam negeri Indonesia untuk produksi tahu Sari Murni Bapak Aco dengan memperhatikan kualitas kacang kedelai sehingga dalam proses produksi menghasilkan tahu yang tinggi.

c. Hotspot selanjutnya permasalahan produksi kacang kedelai ditingkat petani atau perkebunan, dimana untuk menghasilkan kacang kedelai memerlukan pembukaan lahan pertanian. Pembukaan lahan pertanian skala besar memerlukan mesin-mesin pertanian, air dalam jumlah yang banyak, pestisida, herbisida dan sistem irigasi yang memerlukan air dalam jumlah besar. Kemudian dengan pemakaian pestisida dan herbisida dapat menimbulkan pencemaran tanah dan air tanah.

Penggunaan lahan pertanian dengan tidak menebang hutan primer tapi menggunakan lahan yang khusus untuk pertanian kacang kedelai dan bekerja sama dengan petani lokal. Selain itu perbaikan yang dilakukan adalah dengan menggunakan pestisida dan herbisida yang ramah lingkungan, sehingga mengurangi dampak terhadap pencemaran air tanah dan tanah.

d. Kemudian untuk meningkatkan pendapatan dan kualitas produksi pabrik tahu SM Bapak Aco perlu dilakukan :

1. Ampas tahu hasil dari penyaringan bubur tahu tahap pertama masih mengandung banyak sari kacang kedelai, sehingga untuk meningkatkan produksi tahu dapat dilakukan pengolahan tahap kedua, untuk mendapat hasil tahu yang banyak.

2. Kemudian perbaikan lain dari proses produksi adalah asam cuka $\left(\mathrm{CH}_{3} \mathrm{COOH}\right)$ yang digunakan untuk menggumpalkan tahu diganti dengan bahan alami antara lain menggunakan Sari Air Laut (SAL) dengan pertimbangan agar dapat menghasilkan tahu yang berkualitas, menyehatkan dan ramah lingkungan ketika tahu menjadi limbah padat ditingkat konsumen.

3. Penanganan limbah ampas tahu dapat digunakan untuk membuat produk-produk yang memiliki nilai ekonomi tinggi, misalnya untuk membuat oncom, tempe gembos, pakan ternak, kerupuk, abon, dan roti ampas tahu.

\section{Kesimpulan}

Dari hasil perhitungan LCA menunjukkan bahwa terdapat 5 kategori dampak lingkungan tertinggi, yang dihasilkan dari proses produksi pabrik tahu Bapak Aco dengan hasil sebagai berikut: Acidification $27,92294 \mathrm{~kg} \mathrm{SO}_{2} \mathrm{eq}$, Eutrophication 1,987027 $\mathrm{kg} \mathrm{PO}_{4} \mathrm{eq}$, Global warming 4026,078 $\mathrm{kg} \mathrm{CO}_{2} \mathrm{eq}$, Human toxicity 436,9892 kg 1,4-DB eq, dan Photochemical oxidation 0,085625 $\mathrm{kg} \mathrm{C}_{2} \mathrm{H}_{4}$ eq. Penelitian ini menunjukkan bahwa 
tahapan penggilingan dan perebusan tahu merupakan tahapan yang berkontribusi besar terhadap dampak lingkungan yang meliputi: acidification, eutrophication, global warming, human toxicity dan photochemical oxidation. Perhitungan dengan aplikasi openLCA terlihat bahwa hotspot permasalahan lingkungan yang paling besar adalah pada pemakaian energi pada saat proses produksi tahu antara lain, steam boiler untuk merebus bubur tahu dengan bahan bakar sisa gergaji kayu dan biogas, listrik PLN untuk menggerakkan pompa air dan mesin penggilingan kacang kedelai menjadi bubur tahu. perbaikan yang dilakukan antara lain melakukan modifikasi peralatan, membuat peralatan yang ada lebih efisien dan tidak boros. Technology change, yaitu mengganti teknologi baru yang lebih efisien atau menghasilkan lebih sedikit limbah. Better process control, yaitu memantau dan mengontrol proses dan peralatan yang digunakan sehingga mereka selalu berfungsi sangat efisiensi dan dengan tingkat pemborosan terendah. Input change, yaitu memilih input yang efisien, efektif dan/atau menimbulkan bahaya minimum untuk lingkungan dan kesehatan manusia.

\section{Ucapan Terima kasih}

Penulis mengucapkan terima kasih pada lembaga penelitian dan pengabdian masyarakat, Universitas Kristen Surakarta, yang telah memberikan dana hibah penelitian Tahun Akademik 2020/2021, sehingga penulis dapat menghasilkan artikel penelitian ini.

$\begin{array}{ll}\text { 6. Singkatan } \\ \text { LCA } & \text { Life Cycle Assesment } \\ \text { PROPER } & \text { Program Penilaian Peringkat Kinerja Perusahaan } \\ \text { LCI } & \text { Life Cycle Inventory } \\ \text { LCIA } & \text { Life Cycle Inventory Assesment } \\ \text { Kwh } & \text { Kilo watt Hours } \\ \text { EPD } & \text { Environmental Product Declaration } \\ \text { GWP } & \text { Global Warming Potential } \\ \text { BOD } & \text { Biological Oxygen Demand } \\ \text { COD } & \text { Chemical Oxygent Demand } \\ \text { SAL } & \text { Sari air laut } \\ \text { RECP } & \text { Resource efficiency and Cleaner Production } \\ \text { Kwh } & \text { Kilo watt hours } \\ \text { IPCC } & \text { Intergovernmental Panel on Climate Change } \\ \text { PLN } & \text { Perusahaan Listrik Negara }\end{array}$

\section{Daftar pustaka}

[1] B. Yudhistira, M. Andriani dan R. Utami, "Karakterisasi: limbah cair industri tahu dengan koagulan yang berbeda (asam asetat dan kalsium sulfat)," J. Sustain. Agric., vol. 31 (2), hal. 137-145, 2016.

[2] D. A. Dornfeld, Green Manufacturing: Fundamentals and Applications, 1st ed. New York: Springer, 2013.

[3] A. D. Astuti, "Potential analysis of environmental impact of sugarcane plantation using life cycle assessment (lca) approach," J. Litbang Kabupaten Pati, vol. 15 (1), hal. 53, 2019.

[4] J. Wahyudi, "Penerapan life cycle assessment untuk menakar emisi gas rumah kaca yang dihasilkan dari aktivitas produksi tahu," University Research Colloquium, hal. 475-479, 2017.

[5] ISO 14040, International Organization and For Standardization, Environmental management - LCA Principles and Framework, 2006.

[6] ISO 14040, Environmental Management-Life Cycle Assesment-Principle and Framework, 2016.

[7] K. Siregar, "ILCAN Training Series of Life Cycle Assessment (ITSoLCA) - LCA PROPER," in Indonesia Life Cycle Assesment network, 2021, pp. 23-24.

[8] KLHK, Peraturan Menteri Lingkungan Hidup Dan Kehutanan Republik Indonesia Nomor 1 Tahun 2021 Tentang Program Penilaian Peringkat Kinerja Perusahaan Dalam Pengelolaan Lingkungan Hidup, 2021.

[9] A. A. R. Setiawan, "Application of LCA in Energy And Material Industries. Setiawan Pusat Penelitian Kebijakan Manajemen Iptek \& Inovasi, Lembaga Ilmu Pengetahuan Indonesia arief_ars_ti01@yahoo.com Workshop Penerapan LCA di Industri Bidang Energi dan Material,” 2020. 
[10] Anonim, “OpenLCA,” GreenDelta, 2013. https://www.openlca.org/ (accessed Jul. 04, 2021).

[11] M. S. Dr A. Ciroth, C. Di Noi, T. Lohse, openLCA 1.9 Comprehensive User Manual, 1.103. Berlin: GreenDelta, 2019.

[12] GreenDelta GmbH, “openLCA Nexus,” Greendelta, 2021. https://nexus.openlca.org/ (accessed Jun. 26, 2021).

[13] IPCC, Guidelines for National Greenhouse Gas Inventory Volume 2 Energy, 2006.

[14] A. D. Astuti, "Analisis potensi dampak lingkungan dari budidaya tebu menggunakan pendekatan life cycle assessment (LCA)," J. Litbang, vol. 15 (1), hal. 60, 2019.

[15] I. E. Winar, T.R. Wahyudi dan Y. Doddi, "Estimasi dinamik jangka panjang terhadap kualitas air untuk pengendalian eutrofikasi pada Waduk Jatiluhur," J. Tek. Hidraul., vol. 3 (1), hal. 1, 2012.

[16] A. Arba'i, R. Faridz dan A. A. Jakfar, "Life cycle assessment (LCA) pada produk jamu kunyit asam di UD. Al Mansyurien Kamal Bangkalan,” Agroindustrial Technol. J., vol. 3 (2), hal. 78-94, 2019.

[17] A. F. Rahmani dan M. Handajani, "Efisiensi penyisihan organik limbah cair industri tahu dengan aliran horizontal subsurface pada constructed wetland menggunakan Typha angustifolia," J. Tek. Lingkung., vol. 20 (1), hal. 78-87, 2014.

[18] V. R. Piers Forster, Changes in Atmospheric Constituents and in Radiative Forcing Chapter 2. 2007.

[19] Direktorat Jenderal Ketenagalistrikan Kementerian ESDM, Pedoman Penghitungan dan Pelaporan Inventarisasi Gas Rumah Kaca Direktorat Jenderal Ketenagalistrikan Kementerian ESDM 2018 Bidang Energi - Sub Bidang Ketenagalistrikan, Jakarta, 2018.

[20] V. V. Chandra, S. L. Hemstock, O. N. Mwabonje, A. D. R. N'Yeurt and J. Woods, "Life cycle assessment of sugarcane growing process in Fiji," Sugar Tech., vol. 20, pp. 629-699, 2018.

[21] Anonim, "Resource Efficient and Cleaner Production (RECP)," United Nations, Industrial Development Organisation, 2020. https://www.unido.org/our-focus-safeguarding-environment-resource-efficientand-low-carbon-industrial-production/resource-efficient-and-cleaner-production-recp (accessed Jul. 11, 2021). 